\title{
Introducción de la enseñanza mutua en las escuelas de Cuba, Guatemala y México
}

\author{
Introduction of mutual teaching in schools of Cuba, Guatemala and \\ Mexico \\ Introdução do ensino mútuo nas escolas de Cuba, Guatemala \\ e México
}

\author{
Osvaldo Granda Paz ${ }^{1}$ \\ Universidad de Nariño (Colombia)
}

Recepción: 24/10/2016

Evaluación: 13/06/2017

Aceptación: 24/08/2017

Artículo de Investigación - Reflexión

DOI: https://doi.org/10.19053/01227238.7577

\section{RESUMEN}

En este artículo se hace un registro y descripción del itinerario de la llegada de la enseñanza mutua en Cuba, Guatemala y México, la participación de la Sociedad Económica de Amigos del País de la Habana, la Real Sociedad Económica de Amantes de la Patria de Guatemala, de la Real Junta de Caridady Sociedad Patriótica para la Buena Educación de la Juventud de Puebla, y de algunos preceptores que en la segunda década del siglo XIX logran impactar y transformar la educación en primeras letras en estos países. Para ello se hace un seguimiento a través de documentación epocal contextualizando las acciones de las asociaciones y dando relieve primordialmente al evento de la introducción del método de enseñanza mutua. Se establece la cronología para identificar desde dónde fue tomado el método lancasteriano y se establecen los primeros actores en su aplicación con sus respectivas caracterizaciones.

Palabras clave: enseñanza mutua; Cuba; México; Guatemala; sociedades patrióticas; educación; escuela lancasteriana.

1 Doctor en Ciencias de la Educación. RUDECOLOMBIA-UDENAR. Docente de la Universidad de Nariño. Pertenece a los grupos de investigación HISED e HISULA. Email: osgranda@udenar.edu.co 


\section{ABSTRACT}

This article presents and describes the itinerary of the arrival of mutual education in Cuba, Guatemala and Mexico, the participation of patriotic societies such as: the Sociedad Económica de los Amigos del País de la Habana, the Real Sociedad Económica de Amantes de la Patria de Guatemala, the Real Junta de Caridad y Sociedad Patriótica para la Buena Educación de la Juventud de Puebla, and some preceptors that impacted and managed to transform the primary education in these countries during the second decade of the 19th. To this end, an epochal documentation follow-up was carried out by contextualizing the actions of the associations and giving prominence to the introduction of the mutual teaching method. The chronology is established to identify where the Lancasterian method was taken from and the first actors who applied it are characterized.

Keywords: mutual teaching; Cuba; Mexico; Guatemala; patriotic societies; education; Lancasterian school.

\section{RESUMO}

Neste artigo se faz um registro e descrição do itinerário da chegada no ensino mútuo em Cuba, Guatemala e México, a participação da Sociedade Econômica de Amigos do País de Havana, a Real Sociedade Econômica de Amantes da Pátria de Guatemala, da Real Junta de Caridade e Sociedade Patriótica para a Boa Educação da Juventude de Puebla, e de alguns preceptores que na segunda década do século XIX conseguiram impactar e transformar a educação de primeiras letras nesses países. Para isso se fará uma sequencia por meio da documentação da época, contextualizando o que foi realizado pelas associações, dando relevo primordialmente ao evento da introdução do método de ensino mútuo. Será estabelecida a cronologia para identificar de onde foi tomado o método lancasteriano e foram estabelecidos os primeiros atores em sua aplicação, com suas respectivas organizações.

Palavras-chave: ensino mútuo; Cuba; México; Guatemala; sociedades patrióticas; educação; escola lancasteriana.

Contextualización: Idioma Maya Achi Contextualizador: Alejandro Pedro de la Cruz y de la Cruz

Ministerio de Educación de Guatemala

\section{CH'UTIN TZIJ}

Tz'ib'anik chupan jun cholajil rilom béyal ruponik tijonik ronojel chupam Cuba, Guatemala i México, xe'ok b'i je nimaq chi re rajaw pwaq qachalal Habana, qonojel utz k'uxaj re jiyub' ta'aj Guatemala, utz. K'uxaj molom utz kik'ux i molom aj tinimit re utz k'utunel chike ab'omab' altomab' re Puebla, i jun chik kib'im qanok ukab' junab' re XIX xe tikiche' chu minik re tinamit. Chike i keqa' an jun b'eyanik rumal uwujil ya'tal kanok chi antalik kumal nimaq taq moloj 'ibelib' kiya'o ucho'ab' nab'el taqchak jeqom kanoq usuk' k'utunik kanoq. Kajaqik cholom ilb'al pa saqil wi k'ut b'al lancasteriano qakilb'elre nab'e nimaqtaq ch'ob'onel i wach $\mathrm{u}^{\prime}$ anik antalkanok.

Ru k'ux taq tzij: chaqaxol k'utunik; Cuba; México; Guatemala; nimlaj moloj; tijonik, tijob'al lancasteriana.

\section{INTRODUCCIÓN}

La implantación de la enseñanza mutua en la segunda década del siglo XIX, en América Hispana, ha sido objeto de continuas referencias por parte de algunos 
investigadores de la Historia de la Educación. Se destacan los aportes para los casos chileno-argentino y mexicano con los trabajos pioneros de Domingo Amunátegui y Dorothy Tanck de Estrada que inician su historia y análisis respectivamente. A ellos les siguen de forma intermitente trabajos históricos de alguna manera globalizantes y se avanza, en los últimos años, con análisis incluso del carácter semiótico de la educación. Pero en cualquiera de las vertientes la localización de la documentación primaria es de vital importancia, pues solo así no se seguirán repitiendo datos y acontecimientos que no pueden ser refrendados, y algunos producto de la imagología que sobre el lancasterianismo se creó desde su introducción en nuestros países.

En este sentido también debemos tomar en cuenta que fue a partir de la contribución e innovaciones de la "escuela lancasteriana" que las instituciones educativas se modernizaron en Europa y América, por consiguiente cualquier aporte que se pueda hacer para avanzar en el conocimiento de dicho proceso histórico justifica volver sobre el tema desde cualquier paradigma investigativo. En este estudio se hará desde la historia de la educación.

Por ello el objetivo de esta indagación se enfoca a dar claridad histórica sobre el derrotero de la introducción de la enseñanza mutua en la región, describiendo de manera documentada cómo llega primero a Cuba y cómo de ahí pasó a México. Se corrobora los aportes de algunos maestros y se precisa cronológicamente sus fundaciones. Se aborda este problema a través de la revisión de documentos de archivo, algunos manuales lancasterianos y a través del seguimiento documental de las primeras incursiones de maestros que conocieron este método de enseñanza. Igualmente se logra ubicar las primeras publicaciones lancasterianas en Cuba, México y Guatemala, cuyo estudio se deja para otra presentación.

El conocimiento de dichas evidencias documentales dan las bases para establecer la historia del derrotero lancasteriano en América Hispana lo cual permitirá hacer estudios comparativos entre las historias y producciones locales.

Desde el método de la Historia de la Educación Comparada, se asumen aspectos básicos del problema. Primero se ubica históricamente, de manera documental, la introducción del método de enseñanza y a los maestros que lo hicieron; subsecuentemente se reconocen los primeros documentos creados en su entorno. Esto permitirá comprender la aparición de las escuelas, sus características y materiales escolares entre los que cabe destacar los manuales. En este artículo se precisarán, por tanto, el curso histórico y los primeros productos de la introducción de la "escuela lancasteriana". Por tanto no se trata de un análisis de los documentos, pues en esta primera fase se trata de ubicarlos y determinar su cronología respectiva. En relación a las fuentes tanto primarias como secundarias, abundante en casos como el mexicano, solo se toman en cuenta las estrictamente necesarias.

Después de hacer el recorrido sobre el itinerario de la enseñanza mutua y cómo de su introducción en Cuba, luego pasó a México y posteriormente a Guatemala, podemos concluir reconociendo la importancia que tuvieron las sociedades y asociaciones civiles que con gran facilidad dieron en la posibilidad de asumir este tipo de enseñanza. Bastaba tener una referencia básica del método, para que 
se tomara y se aplicara como se hizo en Puebla y México después de conocer la información que publicó la Real Sociedad de Amigos del País de la Habana con lo cual, debemos resaltarlo, Cuba fue el primer territorio de lo que hoy compone América Latina y El Caribe, que tomo el método y lo aplicó en sus escuelas.

La importancia de hacer este recorrido histórico radica en que permitirá a los interesados en el tema comprender mejor y hacer estudios comparativos de los procesos locales, establecer la introducción de este "método", conocer sus antecedentes, explicar sus desarrollos y su duración. Se hace evidente, por ejemplo, la necesidad de investigación puntual sobre las características propias del surgimiento y primeros desarrollos de la enseñanza mutua en la isla de Cuba, El Caribe y Guatemala, y el papel de las Sociedades de Caridad y Económicas de Amigos del País tanto aquí como en otros países hispanoamericanos. Este trabajo permitirá también tener mejor conocimiento de lo producido en América Hispana respecto de la implantación de este nuevo método de enseñanza, el cual, como en aquellos países donde se había aplicado, cambia y generaliza la educación primaria.

\section{Aspectos preliminares}

Desde su aparición en el contexto español, las Sociedades de Amigos del País y las Juntas de Caridad estuvieron inclinadas a promover la educación del pueblo. ${ }^{2}$ Para ello utilizaron no solo su influencia política sino sus propios recursos humanos y económicos. En espacios como el hispanoamericano, en la tardocolonia, llegó este influjo de las experiencias peninsulares, experiencia que se profundiza en la primera mitad del siglo XIX y que se expande con menor potencia en la segunda mitad. En muchas poblaciones las Juntas de Caridad tuvieron especial injerencia en el desarrollo educativo, pero en la mayoría fueron las Sociedades de Amigos, Sociedades Económicas y Sociedades Patrióticas las que se interesaron por difundir y generalizar la educación fundando escuelas públicas, imprimiendo textos y otorgando premios. El preponderante papel que tuvieron en Hispanoamérica también debe sopesarse dada la expatriación de los jesuitas desde 1767 que dejó un vacío en el campo de la enseñanza en todos sus niveles.

En España, las Sociedades Económicas de Amigos del País toman el ejemplo de algunas sociedades europeas. De este modo surge, guiada por Floridablanca, en 1764, la Sociedad Bascongada y luego, al amparo de las reformas borbónicas y por lo expuesto en sus discursos, Rodríguez de Campomanes, las sugiere, promueve y patrocina en todo el país.

Desde entonces alcanzaron excelentes resultados, particularmente en el campo educacional y fue así que sociedades como la bascongada, matritense, gaditana, sevillana y mallorquina, para citar algunos ejemplos, encontraron

2 En 1764, siguiendo el ejemplo de otros países europeos, se había conformado la Real Sociedad Bascongada de los Amigos del País que será tomada como ejemplo en toda España para las sociedades que se organizan posteriormente apoyadas especialmente por Rodríguez de Campomanes. Años después Carlos III, en marzo de 1778, emitió una real cédula estableciendo la Junta General de Caridad con la que se inicia este tipo de establecimientos cuya atención se dirigía a las clases populares y a los pobres. 
émulos en las colonias de ultramar. Bien, motivados por algunos españoles que pasaron a América y sabían de sus alcances, o bien porque algunos criollos se relacionaron con miembros de las sociedades españolas, llegando incluso a ser socios correspondientes. Recordemos el importante papel que jugaron los individuos que pertenecieron a la bascongada en Guatemala, Perú, Cuba y México. ${ }^{3}$

Pero dicha emulación fue propiciada, además, a través de sus publicaciones, las cuales permitieron conocer la organización y áreas en las que actuaban. En este orden de ideas mencionemos, en relación a este aspecto, que los alcances de las sociedades económicas fueron conocidos gracias, especialmente, a la circulación de sus memorias y estatutos.

Encontramos, por consiguiente, que varios tomos de las memorias de las sociedades matritense y bascongada se divulgan, hacia 1784, en México, donde se empiezan a gestionar estas agrupaciones imitando las de la península. Además se distribuían copias del texto Discurso sobre las ventajas que pueden producir al Estado las Sociedades Patrióticas, como premio a los estudiantes más adelantados en los certámenes públicos, así ocurre con los alumnos de la Escuela Patriótica de Veracruz ${ }^{4}$ patrocinada igualmente por la Sociedad Patriótica local. ${ }^{5}$ Esta escuela llegó a tener mucha importancia, tanto que el virrey Revillagigedo tomó parte para desarrollar su plan de estudios. ${ }^{6}$

A la par, podrá comprobarse la circulación de tales obras en la Isla de Cuba, donde la Sociedad Económica de Amigos del País de la Habana incluía en su biblioteca el Ensayo de la Sociedad Bascongada de los Amigos del país, de 1766, conocido regularmente junto a los Extractos de las juntas celebradas por la Real sociedad bascongada de los amigos del país, de 1772, y otras. ${ }^{7}$ De idéntica manera pasa en otros espacios, como en la capital del virreinato de la Nueva Granada, donde circulaban los siguientes textos: Ensayo de la Sociedad Bascongada de los Amigos del país de 1766, Colección de las memorias premiadas, y de las que se acordó se imprimiesen sobre los cuatro asuntos que por encargo particular publicó la real sociedad económica de amigos del país de esta corte en el suplemento de la gazeta de 14 de agosto de 1781 publicado en Madrid en la imprenta real en 1784, y Discursos que don Joseph Agustín Ibáñez de la Rentería presentó á la Real Sociedad Bascongada de los Amigos del País en sus juntas generales de los años de 1780, 81 y 83 de 1790, que en la actualidad forman parte de los fondos de la Biblioteca Nacional de Colombia.

A lo anterior, pronto se sumaron producciones locales como el Extracto de las primeras juntas, celebradas por la Sociedad Económica de Amigos del País en la villa de

3 Para el caso de los bascongados de México puede verse la obra de María Cristina Torales Pacheco. Ilustrados en la Nueva España: los socios de la Real Sociedad Bascongada de Amigos del País. (México: Universidad Iberoamericana, 2001). Allí de manera detenida y profunda se da cuenta de la relación académica que mantuvieron los socios mexicanos de dicho cuerpo.

4 Gazeta de México. México: No 2, 24 de enero de 1786 (p. 27). Suplemento a la Gazeta de México, No. 45, de 22 de agosto de 1786 (p. 187), y Suplemento a la Gazeta de México. México, 20 de noviembre de 1787 (p. 457).

5 Gazeta de México. México: No. 11, del 6 de junio 1788 (p. 81).

6 Más información sobre la estructura y estudios en la Escuela Patriótica de Veracruz en (Luque Alcaide 1970).

7 El inventario de la biblioteca puede consultarse como "Lista de obras existentes en la Biblioteca de la Real Sociedad Patriótica de La Habana" inserto en el "Expediente general sobre la reforma de los estudios en la isla de Cuba”. AHN: ULTRAMAR, 126, Exp.10. 
Mompox, de 1784 y los varios volúmenes de memorias de la Sociedad Económica de Amigos del País de La Habana.

Por ende es de suponer que lo mismo sucede en todas las colonias españolas. Sea como fuere, la idea de crear sociedades económicas o sociedades patrióticas como se les llamó en algunas ciudades, cundió en las dos últimas décadas del siglo XVIII. La primera de ellas, de la que tenemos noticias, corresponde a una Sociedad de Amigos del País que, contando con la debida aprobación se quiso establecer, hacia 1781, en la provincia de Antioquia. Luego encontramos a la Sociedad Económica de Amigos del País de Santa Cruz de Mompox, fundada y aprobada el 17 de agosto de $1784,{ }^{8}$ cuya vida se extiende por un breve lapso y cuyas realizaciones están por investigarse. En este mismo tiempo como se mencionó antes, en Veracruz, México, funcionó una Sociedad Patriótica de Amigos del País. Asimismo, por estos años, hubo intensiones de fundar una en Yucatán gracias al conocimiento que se tenía de la sociedad guatemalteca por parte de algunos suscriptores locales de la prensa del vecino país. ${ }^{9}$

Años más tarde se intentó fundar la Sociedad Económica de Amigos en la ciudad de México y de ello se conocen documentos como el enviado en abril de 1799 por el Virrey Miguel de Azanza al Ministro de Estado, en nombre de algunos vecinos que movidos por el "interés público" solicitan su aprobación para instalar y ponerla en marcha acorde al "Proyecto y Plan de una Sociedad Económica en México", ${ }^{10}$ lo cual por terceras razones no se pudo llevar a buen término. Luego vendrán la Sociedad Económica de Amigos del País de Santiago de Cuba fundada en 1787; la de Lima fundada en 1790; de La Habana y de Quito fundadas en 1792; la Real Sociedad Económica de Amantes de la Patria de Guatemala fundada en 1795; y otras posteriores como las de Santa Fe, Santiago de Chile, Cartagena, Lima, Buenos Aires, etc.

Estas sociedades incluían en sus estatutos capítulo especial al fomento de la educación, y lo ponían en práctica fundando escuelas de primeras letras y academias para enseñar oficios, y a través del patrocinio de publicaciones que difundían métodos y prácticas pedagógicas, como se cuenta inicialmente en lo aportado por la bascongada que había apadrinado la publicación de la obra de Palomares "El maestro de leer..." de amplia difusión en España y América, o como ocurrirá entrado el siglo XIX con la gaditana y la publicación del Manual de enseñanza mutua... que tanto promovió la educación de los niños en España y que, para muestra de su difusión, también llegó a sus corresponsales en Guatemala.

Por consiguiente no solo se promovían a través de personas conocedoras de su funcionamiento sino a través de las bibliotecas ilustradas que destacaban, en sus fondos, las memorias de las sociedades madrileña, bascongada y segoviana, para recordar las más conocidas. Así pasó en el caso de José Pérez Calama inicialmente

8 Extracto de las primeras juntas, celebradas por la Sociedad Económica de Amigos del País en la villa de Mompox, provincia de Cartagena de Yndias. Desde el 12 de septiembre hasta el 19 de diciembre de 1784. Santa Fe: Antonio Espinosa de los Monteros [1784].

9 Puede verse la breve reseña sobre este punto en Robert Jones Shafer, The Economic Societies in the Spanish World [1763-1821]. (Syracuse: Syracuse University, 1958), 156-157.

10 AGI: ESTADO, 28, N.31. Carta nº 92 del Virrey de Nueva España, Don Miguel José de Azanza a Don Francisco Saavedra, Ministro de Estado. 
en México y después, durante su obispado en Quito. Los promotores locales en las colonias españolas de ultramar, igualmente fueron personajes que tendrán una participación de primera línea en los hechos políticos y económicos de estos territorios. Baste recordar que Eugenio Espejo y Antonio Nariño fueron quienes en Santa Fe y Quito, respectivamente, promovieron este tipo de asociaciones. Entonces, fue a través de estas sociedades patrióticas y/o económicas de amigos del país como se debatían y fomentaban las ideas liberales sobre educación, cambio-sociales y económicos, y desde luego de independencia.

En cuanto a las Juntas de Caridad, iniciadas en Madrid hacia 1778, llegan a México en distintas épocas: en Veracruz y Puebla por iniciativas ligadas a proyectos educativos y, en México, a problemas de salud, durante la epidemia de viruela que azotó la capital del virreinato por 1797. Junta disuelta el año siguiente según consta en documentos epocales. También al comenzar el siglo XIX, en 1802, desde Monterrey, hubo interés manifiesto por parte de sus habitantes por crear una Junta, como puede verse en un oficio de Andrés de Imaz dirigido al Secretario de Estado en el cual resalta los efectos benéficos para la educación pública que traería su establecimiento a semejanza de la Real Junta General de Caridad, por lo cual pedía se le envie "el plan o constituciones de aquélla". ${ }^{11}$

Estas sociedades siguiendo la línea de la vascongada y matritense, enfatizaron su interés en la educación y, con frecuencia, obsequian ejemplares de los libros que las corporaciones españolas patrocinaban, como se hizo con El maestro de leer...al finalizar el XVIII, y años más tarde con algunos manuales lancasterianos que se tradujeron del inglés o se tomaron del manual de la gaditana. De otra parte se encuentran casos como la sociedad de la Habana que promueve entre sus socios la producción de textos educativos de divulgación y algunas cartillas propias. A la par de ello las juntas de Caridad hacían lo propio, a veces para obtener fondos, como lo hizo la Junta de Caridad de Leganés en $1791^{12}$ que pide licencia para publicar Noticias varias y curiosas de Madrid, o para difundir textos religiosos como, a guisa de ejemplo, lo hace la Real Junta General de Caridad, de Madrid, que pidió en 1799 licencia para reimprimir El Catecismo de la doctrina cristiana de Ripalda y el Catecismo histórico o compendio de la historia sagrada y de la doctrina cristiana de Fleury. ${ }^{13}$ Acción que repite la Real Junta de Caridad y Sociedad Patriótica para la Buena Educación de la Juventud de Puebla, al reimprimir el texto lancasteriano ya publicado por la Sociedad de Amigos del País de La Habana.

\section{La Sociedad Económica de Amigos del País de La Habana}

En el contexto cubano dos fueron las principales sociedades a finales del siglo XVIII, la de Santiago de Cuba erigida en 1787 y la de la Habana a la cual

11 AGI: ESTADO, 43, N.37

12 AHN: CONSEJOS, 5557, Exp.35

13 AHN: CONSEJOS, 5563, Exp.29 
se concedió autorización para que funcionara desde finales de $1792^{14}$ pero que celebró su sesión inaugural, con una decena de socios, en enero del año siguiente, ${ }^{15}$ misma que tendrá varios nombres en sus diferentes épocas: Sociedad Económica de Amigos del País y Sociedad Patriótica serán los más duraderos.

Esta sociedad desde su fundación contó con varias secciones dedicadas especialmente a la Agricultura, la Educación y la Literatura. La sección de educación, despliega una actividad de gran importancia desde la segunda década del siglo XIX. A partir de 1815 se constituye en un polo de desarrollo de la educación cubana y se encarga de introducir no solo en la Isla, sino en toda Hispanoamérica, el método de enseñanza mutua.

En su biblioteca pública, la primera de la isla, se encontraba una selecta muestra de obras de los ilustrados franceses y españoles, entre ellos los más acreditados en temas relacionados con la enseñanza de primeras letras, tales como Rodríguez de Campomanes, Feijoo, Servidori y Anduaga. E igual que ocurrió con las otras asociaciones de Hispanoamérica, pasaron por las manos de sus socios algunos volúmenes publicados por las sociedades de amigos del país ibéricas, entre ellas los de la bascongada, como puede verificarse en el inventario de la Biblioteca incluido en el "Expediente general sobre la reforma de los estudios en la isla de Cuba" presentado junto al informe del comisionado Francisco Arango Parreño, consejero regio para el arreglo de los estudios en la isla. ${ }^{16}$

En 1816, cuando están pasando ya los avatares de la guerra española, cobra nuevos bríos y crea su Sección de Educación para dedicarla al fomento y supervisión de las escuelas de primeras letras, al examen de los aspirantes a maestros y a revisar los exámenes. ${ }^{17}$ Los responsables de esta importante sección, a comienzos del año 1818, se encargaron de analizar, evaluar las posibilidades de aplicación y fomentar el sistema de enseñanza mutua. De ahí que publicaron en las Memorias... de los años 1818 y 1819, artículos extensos sobre este tema. Extendiendo de esta manera la afición que desde finales del XVIII había demostrado cuando se encargaron de publicar, en su segunda época, el Papel Periódico.

Fue a través de la difusión hecha en sus publicaciones que se logró que en la isla se establezcan escuelas lancasterianas $y$, por el conocimiento de estas memorias que se tuvo en Puebla, se inició este sistema de enseñanza en México. En todo caso la inclinación por publicar textos que tuvieran que ver con la educación se prolonga hasta mediados del siglo XIX cuando, incluso, se imprimen cartillas para las escuelas rurales. ${ }^{18}$

\footnotetext{
14 Mediante aprobación real de fecha 15 de diciembre de 1792 se aprobó en Madrid su funcionamiento.

15 En Guía de forasteros de la isla de Cuba y calendario manual para el año de 1814 igualmente se afirma que se estableció en enero de $1793(1814,119)$

16 AHN: ULTRAMAR,126, Exp.10

17 Cfr. Ma. Consolación Calderón España y Ma. Isabel Corts Giner. Ofertas educativas de las Reales Sociedades Económicas de Amigos del País en Latinoamérica [Siglos XVIII-XIX]. (2006).

18 José María Calvo. Cartilla rústica para las escuelas del campo. (La Habana: Severino Boloña, 1842).
} 


\section{La Sociedad de Amigos del País de Guatemala}

Una vez recibida la real cédula de aprobación para su funcionamiento fechada en 21 de octubre de 1795, los miembros de esta sociedad ratificaron los estatutos para comenzar con su emprendimiento ese mismo año. En el primer artículo consignaron taxativamente que uno de sus fines sería "mejorar la educación pública". ${ }^{19}$ Entre sus emprendimientos culturales sobresalientes estuvo, al siguiente año, la convocatoria a un premio para quien escribiera sobre un tema específico, a la manera de los concursos que hacían las academias europeas. De esta manera y por resultar ganador del premio del certamen, se vinculó como socio, Fray Matías de Córdova, en 1797. La sociedad dejó de funcionar por algunos años, debido a la carencia de fondos, sin embargo se restableció a partir de 1810.

Fray Matías se convirtió en un intelectual de prestigio, dedicado a la enseñanza, en particular, de las comunidades indígenas. A su regreso del viaje que realizara a Madrid, entre 1810 y 1812 se convirtió en el primer maestro americano en proponer y practicar un nuevo método para enseñanza de las primeras letras; su primera y segunda edición se hicieron en Guatemala bajo el título de: Método fácil de enseñar a leer y escribir. Este método fue perfeccionado por fray Víctor Flórez, quien, a su vez publicó luego el Método doméstico para enseñar y aprender seguramente a leer y escribir en sesenta y seis lecciones. ${ }^{20}$

En 1819, fray Matías logró que se creara en Chiapas una filial de la Sociedad de Amigos de Guatemala, de la cual fue nombrado vicepresidente. ${ }^{21}$ Se sabe que es en esta época, cuando desde Cádiz la gaditana envió varios ejemplares del manual lancasteriano que había impreso, los mismos que serán conocidos tanto por la sociedad de amigos de Guatemala, como por el ayuntamiento, conjuntamente con una misiva de enero de 1819 de la Sociedad Económica de Amigos del País de Cádiz en la cual les invitaba a participar en las "gestiones educativas" para aplicar la enseñanza mutua. ${ }^{22}$ De esta manera, el maestro Matías de Córdova ${ }^{23}$, propuso al Ayuntamiento abrir una escuela lancasteriana, solicitud que reforzó con la presentación del Manual Práctico...y del Suplemento del Noticioso General. ${ }^{24}$ En este punto hace falta esclarecer la recepción que fray Matías tuvo del manual gaditano en la publicación que en 1824 hace de su propia cartilla.

19 Estatutos de la Real Sociedad Económica de Amantes de la Patria de Guatemala (Guatemala: RSEAPG,1796), 4

20 Irma Contreras García. Las etnias del Estado de Chiapas: castellanización y bibliografías. México: UNAM, 2001.

21 Marco Pérez de los Reyes.«Fray Matías de Córdova. Su vida y su obra.» En Memoria del IV Congreso de Historia del Derecho, de Beatriz Bernal (Coord.), (México: UNAM-Instituto de Investigaciones Jurídicas, 1988), 860.

22 Lubia Esperanza Pineda. La Educación en Guatemala durante el régimen de Mariano Gálvez. (Guatemala: Tesis de Licenciatura USAC, 1991), 12

23 Corresponde a fray Matías de Córdova, miembro de la Sociedad de Amigos de Guatemala desde 1797 y entusiasta de la educación popular.

24 Cfr. (Pineda 1991, 29) El Noticioso General de México, es el mismo periódico editado en México en el cual publicó con asiduidad artículos sobre su "Estudio Académico" el maestro José Ignacio Paz, los mismos que pueden leerse en ejemplares de 1817 y que se continúan hasta 1821. 


\section{La Real Junta de Caridad y Sociedad Patriótica para la Buena Educación de la Juventud de Puebla}

Con el conocimiento que debían tener de los logros de la Real Junta General de Caridad de Madrid y, además, de la que se estableció en México, en Puebla se creó la Junta de Caridad y Sociedad Patriótica para la Buena Educación de la Juventud de Puebla, en el año 1796.

Sus propulsores fueron los religiosos Francisco Pablo Vázquez, que preocupado por la infancia había creado una escuela de primeras letras para niños pobres en abril de 1796, y con esa misma intensión y por la escases de recursos para financiar la enseñanza, había organizado ya la "Obra Pía de Educación de la Ciudad de los Ángeles y su Obispado", y el padre Jiménez de las Cuevas que en 1807 fue el encargado de solicitar licencia para establecer la Junta de Caridad. ${ }^{25}$

Esta Junta siempre se mantuvo atenta a la calidad del método de enseñanza utilizado en la educación que promovía y por ello en 1819, habiendo conocido lo descrito a través de las Memorias de la RSEAPH sobre las escuelas lancasterianas, introduce el método en su escuela, para lo cual logra, con financiación de Joaquín Furlong, miembro de la Junta, la reimpresión del texto publicado por la habanera. Luego en 1824 los miembros de la Junta logran con asentimiento del gobierno del Estado, la apertura de una escuela para niñas.

En cuanto a la aplicación del "método" lancasteriano, no hay documentación suficiente para conocer cuánto tiempo se mantuvo, pero se seguía aplicando en la escuela del Seminario en 1823. ${ }^{26}$ Sin embargo, cabe a la Junta Patriótica de Puebla la responsabilidad de haber aplicado en su escuela la enseñanza lancasteriana por primera vez en México, hecho que debió ocurrir a mediados o finales del año 1818.

En los anteriores hechos confluyen, como se ve, intereses comunes de las asociaciones de particulares empeñadas en el fomento de la educación de las clases populares: de la Real Sociedad habanera, la Sociedad de Amigos guatemalteca, la sociedad gaditana y la Junta de Caridad y Sociedad Patriótica de Puebla, las cuatro confluyen para impulsar la propagación de la enseñanza mutua.

\section{Introducción de la enseñanza mutua en Hispanoamérica}

El recorrido de la enseñanza mutua como sistema educativo ${ }^{27}$ y con aplicación del método que se conocerá bajo la denominación de monitorial o lancasteriano, con un importante antecedente en el trabajo de Andrew Bell a fines del siglo

25 Luis Arturo García Dávalos. "La Real Junta de Caridad y Sociedad Patriótica para la buena educación de la juventud de la ciudad de Puebla de los Ángeles en la América Septentrional y la introducción en Nueva España del método Lancasteriano” (2016, 8-9).

26 Ibídem, y del mismo autor, Teología, sociedad y política en la transición al México independiente. El pensamiento de Pablo Vázquez [1768-1825]. (México: Tesis doctoral en Historia, UNAM, 2015).

27 El sistema de enseñanza mutua que se impone a comienzos del siglo XIX incluye elementos de financiación, como las suscripciones por parte de personajes pudientes, la dotación de espacios físicos y útiles escolares propios, nuevas tareas para los maestros y sus monitores, una relación entre las escuelas y los estados que en Inglaterra continúa de manera similar la tradición de apoyo que se había dado a la escuela escolástica, y en América Hispana se empieza a plantear en una relación directa para que se asuma el papel de estados docentes, habilitando la escuela lancasteriana como método oficial en varios países del continente, etc. 
XVIII, se inicia en Londres en la escuela para niños pobres de Borough-Road, en Southwark, a cargo de Joseph Lancaster. Su funcionamiento si bien se inicia en 1798, se organiza bajo este nuevo sistema en los tres primeros años del siglo XIX.

Con dicha experiencia en 1803, su preceptor publicó: Mejoras para la enseñanza de las clases industriosas de la comunidad, ${ }^{28}$ impulsando así nacional e internacionalmente la expansión del "método". Este mismo año se publicaron, al menos, dos ediciones de este manual, las más conocidas fueron las de 1805 y 1807. Mediante este epítome se propició la elaboración de manuales que se conocerán en el resto de Europa y América. Así, el sistema se conoció rápidamente en Francia y en Estados Unidos. En 1806 se abrió una escuela en Nueva York a la cual prosiguieron las fundaciones de Filadelfia, Nueva Escocia, Georgetown y Cincinnati y más tarde en Washington y Baltimore. ${ }^{29}$

Gracias a la información de que hacía acopio la Sociedad Lancasteriana asentada en Londres expresada en su publicación Origen y progresos de la enseñanza mutua, se conocen avanzadas del "sistema" 30 en Haití y en Dominicana en 1817. Sobre las escuelas de Haití, es la Sociedad Lancasteriana de Londres la que ofrece información en su publicación, allí incluye un aparte del bando público de enero de 1817.

Ahora bien, con estos antecedentes próximos encontramos los desarrollos que se plantean en la Isla de Cuba, pues en agosto de 1814 se publicó en el periódico La cena, de La Habana, un artículo sobre las escuelas lancasterianas en el que se manifestaba, entre otras cosas, que si bien no se proponían para que se generalizaran en el continente y en España "su utilidad para las clases pobres es clara". ${ }^{31}$ Luego gracias a la publicación de las Memorias por parte de la Real Sociedad Económica de Amigos del País de La Habana, se abrió una escuela con el método lancasteriano desde el año $1815^{32}$ y desde entonces fue este un pilar de su labor educativa. ${ }^{33}$

También en 1815, de otra parte, se harán intentos por implantar la enseñanza mutua en Sudamérica. Sabemos que se abrió una escuela en Concepción, Uruguay, en la cual puso en práctica el método lancasteriano el presbítero chileno

28 Con la obra Improvements in education as it respects the industrious classes of the community (containing, a short account of its present state, hints towards its improvement, and a detail of some practical experiments conducive to that end) que en 1803 al menos tuvo dos ediciones,

29 Noticias de ello se incluyen en Report of the British and Foreign school society.Londres: Tylor, 1815, pp. 13-15.

30 Es necesario hacer una aclaración semántica y taxonómica en cuanto a la enseñanza mutua, recíproca, monitorial o escuela lancasteriana. Se habla de sistema como aquella estructura que engloba una forma general cuyas pautas pueden tener variantes específicas, pero que obedecen a un solo patrón. En este caso se trata de la enseñanza monitorial, más conocida como enseñanza mutua que tiene categoría de sistema, dado que ella se estructura de tal manera que se dirige a cumplir con el fin de que sean los mismos estudiantes, quienes "colaboren" en la formación de sus condiscípulos. Las maneras cómo se logra el objetivo de participar de la enseñanza entre ellos, puede tener diferentes métodos y a la vez cada método puede tener diferentes técnicas.

31 Ángel Huerta Martínez. La enseñanza primaria en Cuba en el siglo XIX (1812-1868). (Sevilla: Excma. Diputación Provincial de Sevilla, 1992),105.

32 Ibídem. Por su parte Humboldt reseñó una escuela lancasteriana en la isla, sin embargo la inclusión en su obra Ensayo político... publicada en 1826 hace dudar que la hubiera visto en 1804, año de su segunda estadía.

33 La sección de Educación de la RSEAPH en las Memorias de enero de 1818 menciona su informe de diciembre de 1817 en el cual trata de los adelantos que gracias al trabajo de la Sección se han logrado, entre otras, en la Escuela de la ciudad, de extramuros, y otras en los pueblos del interior, menciona que ha procurado implementar el "sistema de José Lancaster" con las indicaciones ya publicadas como exposiciones en los nos. 4 y 10 de las Memorias. 
Solano García en las postrimerías de ese año. ${ }^{34}$ Posteriormente, a partir de 1819, vendrán las fundaciones adelantadas por James Thompson en Argentina, Chile y Perú; y las de Sebastián Mora a finales de 1821 en Venezuela, Colombia y Ecuador, a las que debe sumarse la lograda por la Sociedad de Amigos del País de Puerto Rico también ocurrida en el año 21.

\section{La enseñanza mutua llega a México por intermedio de la publicación de la RSEAPH}

Para el caso mexicano está documentada la aplicación de la enseñanza mutua en Puebla a mediados o fines de $1818,{ }^{35}$ hecho en el cual tuvo que ver la Real Junta de Caridad y Sociedad Patriótica de dicha ciudad. ${ }^{36}$ Después, en 1819 se pondrá en práctica en la ciudad de México.

En efecto, en Puebla en 1819 se imprimió en los talleres de Joaquín Furlong (miembro de la Junta de Caridad) el manual Plan de escuelas de primeras letras arreglado al nuevo sistema de Lancaster llamado de la enseñanza mutua, ${ }^{37}$ tomado del No. 10 de las Memorias de la Real Sociedad Económica de La Habana que circuló en Cuba el 31 de octubre de 1817, lo cual da un margen para pensar que pudo tenerse noticias concretas de Lancaster desde noviembre de 1817 en el caso de haber obtenido la memoria de publicación mensual, pues la Colección, la primera, de las Memorias de la Sociedad de La Habana que contenía los doce meses del año 1817, circuló en febrero de 1818. De tal manera que, dado el notable interés de la Real Junta de Caridad y Sociedad Patriótica por el tema educativo, pudo haberse puesto en práctica durante este lapso.

Antes de proseguir, sobre este punto se debe comentar que ciertamente el sistema de enseñanza mutua no procede del siglo XIX. Se utilizó, como forma de trabajo, ya desde la antigüedad, y en la época moderna por parte de maestros como Lorenzo Ortiz, en Cádiz; por prescripción de la Ratio Studiorum se utilizó entre los jesuitas, e igualmente por parte de maestros de la Reforma madrileña en las últimas décadas del XVIII, particularmente por Rubio y Anduaga. Pero fue con Bell y Lancaster que se aplicó en tanto sistema y método a la enseñanza popular. Por ello la nota de Tanck $(1973,495)$ referenciada de la Enciclopedia

34 En el Archivo Artigas se constata "un documento que prueba que el mencionado Solano García sacerdote franciscano chileno, hacia fines de 1815 se ofreció, al mismo Artigas, para establecer una escuela pública en el Arroyo de la China. Artigas aceptó la propuesta, y en diciembre de aquel año García ya estaba trabajando en su proyecto..." (Gaudiano 2002, 103). De otro lado Solano logró levantar dicha escuela para lo cual "había inventado unos hornos de cal, el lucro de la fabricación lo invertiría principalmente en la reedificación de la iglesia, en levantar y establecer una escuela lancasteriana” (Barrios Pintos, 1989).

35 Luis García Dávalos en su texto "La Real Junta de Caridad y Sociedad Patriótica para la buena educación de la juventud de la ciudad de Puebla de los Ángeles..." anota que ésta Junta lo conoció desde 1816 "a través de un informe publicado en una Memoria de la Sociedad Económica de Amigos del País de la Habana, que fue reimpreso en la Nueva España con el patrocinio de Joaquín Furlong”. García Dávalos (México: 8/9/2016), 17) Aquí se debe anotar que Furlong, superior de la Congregación de San Felipe Neri, era dueño de una pequeña imprenta.

36 La Real Junta de Caridad y Sociedad Patriótica de Puebla festejó en el mes de julio de 1813 el haber recibido la cédula real de aprobación. Cfr. (De la Torre Villar 1998), 607.

37 No existen testimonios fehacientes de que fuera Fernández de Almanza quien corrió con los costos de impresión de este manual (Guzmán Pérez 2011), 97. 
Británica en la cual se menciona que en México los Betlemitas utilizaron la enseñanza hacia 1800 debe considerarse bajo esta indicación.

La cuestión es que, entre 1818 y 1819, la enseñanza mutua se aplicó en la ciudad poblana y, varios de sus preceptores, tuvieron que conocer y practicar el método lancasteriano. Por ello es probable que fuera uno de estos preceptores, José Ignacio Paz, quien tenía una escuela de prestigio que hizo noticia desde mediados de 1817 hasta mediados de 1818 por haber logrado la protección del gobierno y realizar certámenes públicos de exámenes de sus alumnos de los cuales estuvieron al tanto el Obispo, el Virrey y también el gobierno de la metrópoli. $^{38}$

Este preceptor efectuó un importante despliegue relatando lo ocurrido en los exámenes de su "estudio Académico" en los suplementos del Noticioso General de México números 269 de septiembre de 1817 y 405 de 28 de julio de 1818, así como en los números 395 de 13 de julio y 426 de 23 septiembre de 1818. En ellos todavía no se da noticia de que tuviera conocimiento de la enseñanza mutua o del "método" lancasteriano. Sin embargo, unos meses más tarde ya se declara conocedor del mismo en el prospecto que envió al Ayuntamiento. Es factible que con los periódicos mencionados $\mathrm{u}$ otros subsiguientes donde se hace alusión a las nuevas experiencias educativas, realizadas en México y Puebla, se presentara fray Matías Córdova al ayuntamiento de Guatemala, como se señalará en su punto.

En 1819, Paz se dirigió a la capital novohispana y, entre abril y mayo, publicó el prospecto que hizo conocer del Ayuntamiento. ${ }^{39}$ Allí explica el manejo que dará a su "Estudio académico de primeras letras" donde trasluce su experiencia preliminar en las ciudades de Jalapa ${ }^{40}$ y Puebla. Indica el uso de los catecismos de Ripalda, Astete y las escuelas pías. Enseñaría lectura mediante el silabario y cartillas. Entre sus "asignaturas" anota Gramática, Ortografía y Caligrafía, "arismetica inferior", Dibujo, Elementos de Geometría, Geografía y Música. En esta época aún se declara seguidor de Torcuato Torio de la Riva, pero agrega: que como ya lo ha hecho antes, entre día dedicará "una hora de enseñanza mutua" de gran servicio para leer, escribir, contar y "perorar". ${ }^{41}$ Luego informó al Cabildo que, el 21 de febrero de ese año de 1819, haría la correspondiente inauguración del establecimiento.

38 Cfr. AGI: ESTADO, 41, No. 69 que contiene una Carta de Don Juan González al Secretario de Estado, dando cuenta del estado de la escuela académica de Paz, acompañada de otra documentación relacionada.

39 Sobre la fecha de la llegada de Paz a México se puede decir esto: En 1818 según consta en un documento del AAM [Instrucción Pública: Libro 2477. Legajo 3, 1809-1822 (1819, Expediente 224)] el Comisario de Puebla lo recomienda a finales de 1818, y en noviembre de ese año según una hoja volante impresa (en Puebla) tenía establecido un "Estudio Académico", sus alumnos explicarían algunos puntos de la Doctrina Cristiana a fines de noviembre. Lo cual significa que sí se trasladó como lo advierte en una nota don Juan Gómez del Campo, esto debió ser al iniciarse el año de 1819. Y menciona las medallas de oro y plata que han dado a los niños, El maestro Paz estaba haciendo trámites para obtener licencia de su establecimiento en el mes de febrero de este año de 1819.

40 Manuel Rivera menciona la importancia que tuvo en Jalapa la "Escuela Académica" de Paz y como hacia su presentación con visos acendrados de realismo $(1869,247)$, los mismos que también destacará durante sus premiaciones a los escolares de Puebla.

41 AAM, "Prospecto del estudio Académico" (J. I. Paz 1819), 8. Es muy probable que el maestro Paz conociera la escuela lancasteriana estando en Puebla en el año 1818, a donde llegó procedente de Jalapa en donde por espacio de al menos un lustro había sido maestro de primeras letras, ceñido en alto grado a la tradición colonial. 
De forma paralela el maestro Andrés González Millán dirigió una misiva al Ayuntamiento mexicano, fechada el 14 de mayo, en la cual solicita se le autorice para hacer una "manifestación de enseñanza de niños" 42 y como se ve por el encabezado de su carta: “Andrés González Millán, Director de la escuela de Enseñanza Mutua establecida en la Calle de Capuchinas" se debió adelantar en escasos días a Paz al poner en práctica el método en la ciudad. Por la ayuda que solicita, demuestra que conoce la forma de financiación que las escuelas lancasterianas habían logrado en Inglaterra. ${ }^{43} \mathrm{Su}$ solicitud la hizo pública a través de la prensa local con el siguiente anuncio:

D. Andrés González Millán director de la escuela de enseñanza mutua establecida en la calle de Capuchinas, hará el 30 del corriente en celebridad de los dias de nuestro católico Monarca el SEÑOR DON FERNANDO VII (q.d.g.) a las once de la mañana en la sala consistorial una manifestación del método que observa, y que con general aceptación se va propagando en toda la Europa como el más análogo y ventajoso para instruir en menos tiempo del que comunmente se emplea la juventud de uno y otro sexo. Y persuadido de que muchos padres zelosos de dar una buena educacion a sus hijos querran tener conocimiento de este interesante establecimiento, lo anuncia al público para que concurra el que guste a imponerse del referido método. ${ }^{44}$

En relación a la estancia en Madrid de González Millán, existe comprobación de la realizada antes de octubre de 1813, cuando estando en España, pide solicitud de pasaporte para regresar a Campeche, de donde había llegado en calidad de comisionado del síndico procurador general "para indagar en la causa que se sigue sobre el contrabando en aquella plaza". ${ }^{45}$ Según Tanck Estrada en fecha que no precisa "...estudió cuatro años en el Colegio de Primeras Letras de Madrid, regresando a México en 1819". ${ }^{46}$ De haber sido así pudo conocer la escuela lancasteriana que Kearney abrió allí desde enero del 18; sin embargo, el hecho de que llegara a México en 1819 no exime que lo hiciera estando en Yucatán o en otra ciudad del virreinato.

\section{Las memorias de la RSEAPH y la publicación del artículos lancasteriano}

La RSEAPH conservó, desde sus inicios, tanto como la sociedad de Santiago, buenas relaciones con la bascongada, generando estrechos lasos de amistad, pues tuvo 63 socios. ${ }^{47} \mathrm{Y}$ si bien no se ha estudiado a profundidad la relación de estos socios y su trabajo en la sociedad local, es verificable que el carácter de las memorias que publican siguen el ejemplo vasco y madrileño.

\footnotetext{
42 Según el listado de profesores examinados que ordenó levantar el Ayuntamiento, dictaba clases a 74 niños en 1820.

43 AAM, [Instrucción Pública: Libro 2477. Legajo 3, 1809-1822,(1819, Expediente 223, 4 hojas)].

44 Gaceta del Gobierno de México, jueves 27 de mayo de 1819, Tomo X, No. 67, p. 518.

45 Archivo General de Indias: INDIFERENTE,2141,N.116.

46 Dorothy Tanck Estrada. La educación ilustrada 1786-1836. (México: El Colegio de México, 2005), 158.

47 Gárate, op. cit., 2/6/2016.
} 
Es así que la RSEAPH con el beneplácito del gobierno isleño y con el concurso de la imprenta oficial, publicó mensualmente sus memorias a partir del año 1817, si bien parece que hubo intentos de hacerlo desde el año 15. Estas memorias se publicaron el año 17 mes a mes y en enero de 18 también se publicaron como colección.

En el No. 10 correspondiente a octubre del año 1817 se publicó el artículo "Enseñanza Pública" dedicado a la obra de Lancaster, con un prólogo tomado de The Analectic magazine del año 1816. Pasando en seguida a incluir el Dictamen de la comisión nombrada por la Sección de Educación, sobre si conviene adoptar el sistema de Lancáster en las escuelas de primeras letras de la ciudad de La Habana. Informe firmado por Justo Vélez y Vicente María Rodrigo. La Sección de Educación se había conformado, como se señala en el No. 13 de sus memorias, correspondiente al mes de enero de 1818, desde el mes de agosto de 1817.

Debemos señalar que ya en la memoria de enero, refiriéndose al estado actual de la enseñanza del bello sexo en La Habana, y de su educación, estos mismos autores Rodrigo y Vélez anuncian la importancia del "sistema sencillísimo de Juan Lancaster". ${ }^{48}$

El artículo referido y resaltado aquí, que dio pie a la reimpresión de Puebla en 1818, desarrolla los siguientes aspectos introductorios a manera de dictamen: Facilidad de enseñar a todas las clases del pueblo las primeras letras y ahorro de tiempo. Economía de los gastos de la enseñanza y reparación asombrosa para preparar a cada uno a que raciocine, piense y trabaje por sí.

Prosigue el "Plan de Enseñanza" que la comisión presenta para que la Sociedad lo apruebe destacando los principales elementos de la obra de Lancáster, explicando los siguientes acápites: Clases de lectura, escritura, y de "arismética"; método de enseñar el alfabeto, "Método p. ap. ${ }^{\text {der }}$ á delet. ${ }^{\mathrm{ar}} \mathrm{y}$ á leer" y método para aprender la aritmética; las cuatro reglas del arte de enseñar con la explicación de lo que se hace en sus respectivas columnas; aspectos administrativos para los casos de ausentes, inspección, regla para que los directores (monitores) hagan las acusaciones, los instrumentos y modos de castigo entre los cuales destacan los grillos para las principales faltas cometidas en la escuela; y en cuanto a los honores e incentivos: trata la emulación y premios, una orden de merito, cédulas de premio cuando haya emulación entre las clases. Pasa luego a reseñar la manera como se desenvuelve el trabajo en las aulas evitando el "tono ridículo" en la lectura, como participan los directores y ayudantes, las diferentes órdenes y los mandatos; las papeletas para mandar que vayan á presentar lo escrito y para que vuelvan a la clase, colocación de las pizarras y para cuando se vayan á su casa. Por último trata lo referente a los requisitos para ser director.

Plasman de este modo una buena presentación de los distintos componentes metodológicos y disciplinarios, basados en uno o más de los manuales lancasterianos que circulaban a nivel internacional, pero desde entonces 
adicionan elementos regionales que provienen de la escuela tradicional, como se hará en distintas localidades de la geografía hispanoamericana.

\section{CONCLUSIÓN}

Hemos visto cómo fueron varias asociaciones particulares las responsables de que en la educación hispanoamericana se introdujera el sistema de enseñanza mutua, y hemos recorrido este proceso en Cuba, Guatemala y México. El aporte ofrecido por ellas, con sus propios recursos, fomentando las escuelas de primeras letras, es una actividad que debe resaltarse para entender cómo los gobiernos dejaron en sus manos, como ocurrirá especialmente en México, todo lo relativo a las escuelas. Allá se conformó a partir de 1822 la Compañía Lancasteriana. Esta situación hay que revisarla a todo lo largo y ancho de Hispanoamérica, pues como ocurrió en los países aquí reseñados, también habrá otras ciudades en las cuales se tomará bajo su protección la educación infantil.

En el caso particular que hemos descrito, es difícil establecer la vía de apropiación del texto lancasteriano del cual provino la publicación de las memorias de la RSECPH, pero por lo visto del prólogo efectuado a la presentación del dictamen en la memoria No 10 de 1817, debe provenir de los manuales ingleses. A partir de entonces por el efecto que tiene dicha publicación en México la influencia del sistema de enseñanza mutua en la Educación de México, Guatemala y Cuba se mantendrá por varias décadas.

Se debe resaltar el papel que tuvieron las publicaciones periódicas y la edición de los manuales por parte de las Sociedades de Amigos del País, tanto españolas como americanas, en la renovación, a nivel general, de las escuelas en la Península y sus colonias ultramarinas, como señalamos, centrados en la difusión, en ese caso de la enseñanza lancasteriana.

La aplicación centralista del modelo de Lancáster se replicó en aspectos de dotación de materiales y libros y quizá en un factor más conflictivo, el de la preparación y nombramiento de maestros, esto sin duda influyó en que le salieran múltiples contradictores. Fue frecuente durante este periodo que muchos de los maestros de las escuelas de primeras letras y de los colegios fueran curas y a veces voluntarios, con lo cual no se podía prever los desarrollos que tendrían los ejercicios educativos y las mismas escuelas. En todo esto debe incluirse como uno de los factores preponderantes de dichos desarrollos, la participación de las Sociedades de Amigos el País.

Por consiguieente, frente a los acontecimientos educativos logrados en medio del fragor de las guerras de independencia de los países hispanoamericanos y el profundo deseo de aportarle a la infancia de esta convulsionada época, se debe destacar el mérito que corresponde a las sociedades de amigos del país junto a Solano García, chileno; Paz, Millan y Córdova, mexicanos, y Sebastián Mora colombiano, junto a James Thompson, como iniciadores de la escuela 
lancasteriana en Hispanoamérica, con fines de socialización de la educación en la primera mitad del siglo XIX

De esta manera se estableció en Cuba la enseñanza mutua como queda expuesto en este artículo. Conocido este evento y tomando su ejemplo gracias a la información que incluyó la comisión de educación de la Sociedad Económica de Amigos del País de la Habana en sus Memorias, el método se implantó en México. De este modo podemos tener las tres direcciones desde las cuales llegó la denominada "escuela lancasteriana" o método de "enseñanza mutua" a América Hispana: por la Sociedad de la Habana al Caribe y Mesoamérica, con J. Thompson al Cono Sur (Argentina, Uruguay, Chile y Perú) y con Mora Berbeo a la Gran Colombia (Colombia, Venezuela y Ecuador).

Es importante conocer esta genealogía y poder después explicar los desarrollos locales y también explicar el papel de los gobiernos y de las "sociedades de educación" con cuyo aporte por ejemplo, en México se mantiene este tipo de enseñanza hasta casi terminar la segunda mitad del siglo XIX y en cambio en los países andinos solo permanecerá hasta la década de los 40. También es posible que a partir de este recorrido histórico se pueda presentar cronológicamente y con mayor realce la participación de diferentes maestros, así mismo la aparición de materiales educativos, particularmente los manuales y cartillas lancasterianas.

Ante lo expuesto sobre este proceso de introducción de la enseñanza mutua, se plantea la necesidad de investigar y conocer mejor el proceso que se surtió en la Isla de Cuba, y sobre los alcances que se lograron en Guatemala y Centroamérica. Casos diferentes al de México para el cual hay suficiente documentación, así como algunos estudios puntuales. 


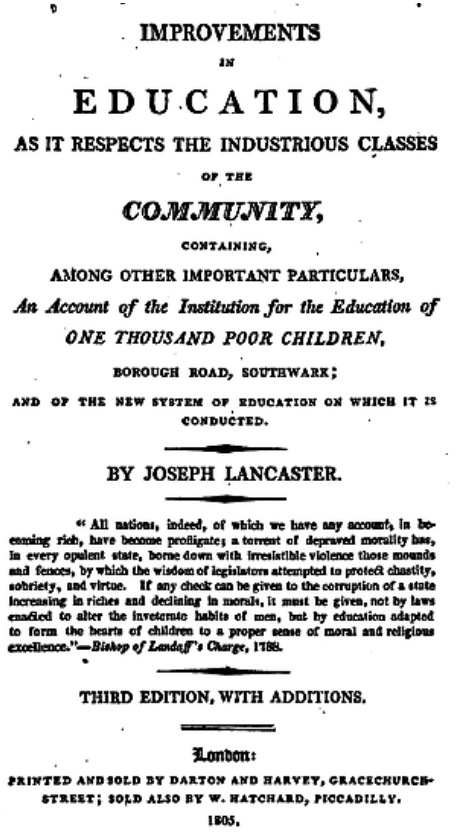

MANUAL PRACTICO

DEL MÉTODO DE MÚTUA ENSEÑANZA

PARA IAS ESCUELAS

DE PRIMERAS LETRAS.

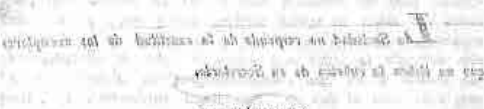

PUBLTCADO

POR LA RBAL SOCUEDAD ICONOMICA DE AMIGOS DEL PASS, DE LA RROVIRCA DE CLDIZ.

CON LICENCIA.

CÁDIZ: IMPRENTA DE HÉRCULES, CALLE DEI. rosakio esquina $l$ LA DEL Dazuarte.

AÑO DE $\$ 818$.

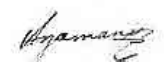

1. Manual publicado por Joseph Lancaster: Improvements in Education: Abridged. Containing a Complete Epitome of the System of Education Invented and Practiced. Londres, 1808. 2. Manual práctico del método de mutua enseñanza para las escuelas de primeras letras. Cádiz: Imp. de Hércules, 1818. 
DE LA REAL SOCIEDAd ECONÒMICA

DE LA HABANA.

2UM. $10=$ DISTRIBUIDO EN 31 DE OCTUBRE DE $181 \%$.

\section{M.}

ENSENANZA PUBLICA. mero que dío un impulso á la educacion pùblica, enseñando los primeros rudimentos de la lectura à toda clase de gentes, ha tenido el mas brillante suceso en Irlanda, cuyos habitantes le han protegido $y$ animado mucho. Con el objeto de difundir los conocimientos generales de su mètodo, viajo por aquel pais en los nถ๊o de 1814 y 1815. Miles de personas oyéron sus lecciones pùblicas $\mathrm{y}$ le honràron con sn aprobacion. Una junta pùblica de Dublin le invitó á que se estableciese en Irlunda, cuya proposicion admitio en medio de inmensos aplausos. El afirma ( $y$ nosotros creemos) que aus planes para establecer escuelas han excitado tode el interes posible, desde Petersburgo hasta KamsChatka, desde Iondres hasta Cincinati donde hay ya una escuela con nuvecientos niños, y desde Invernes hasta Haiti. Dos, de sus discipulos han ido á establecer escuelas en las riveras de San Lorenzo, otros dos al Misisipl, otros han ilo à la Afica, $y$ otro está preparaudose para ir á bengala toca Bena

smigos del sistema de educacion de Lancáster, que se tuvo en Dublin bajo la presidepcia del duque de Leinster, se resolvió que " por

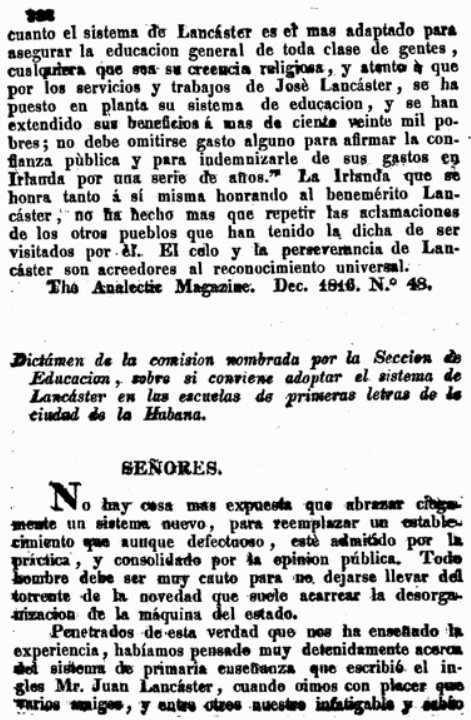

3. y 4. Memorias de la Real Sociedad Económica de La Habana: colección primera que comprende doce números, correspondientes a los doce meses del año 1817. La Habana: Oficina del Gobierno y de la Real Sociedad Patriótica, 1817 (Biblioteca de Nueva York). 

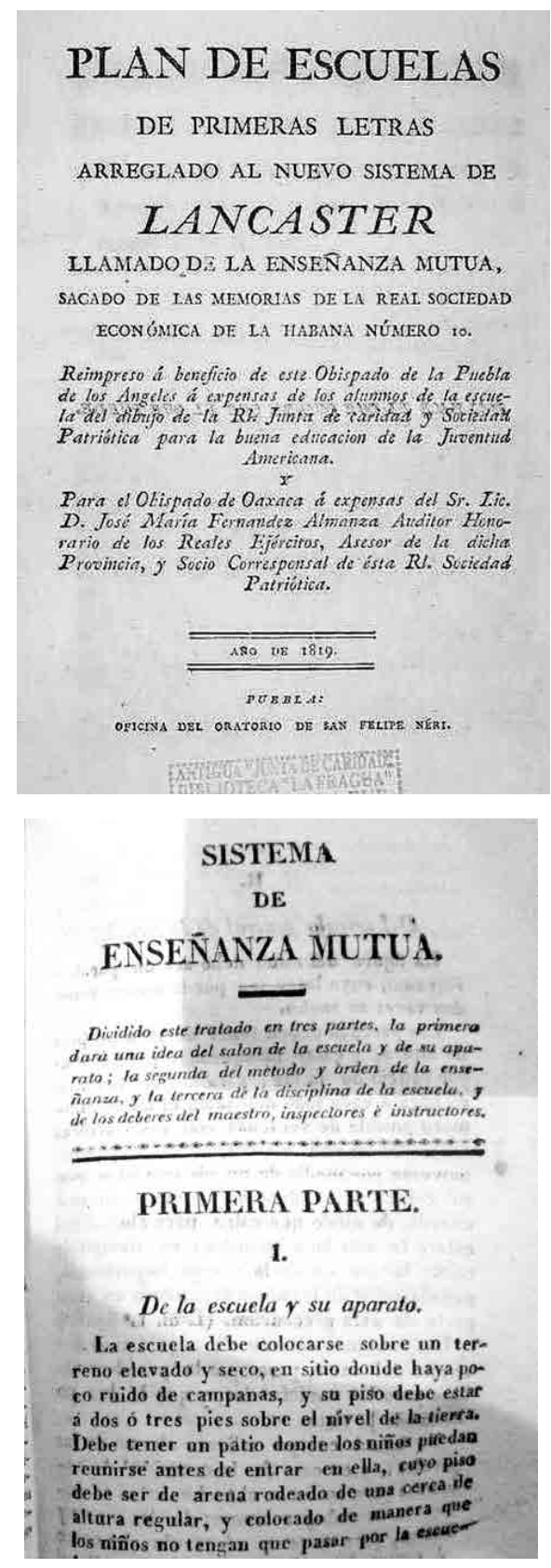

5. y 6. Plan de escuelas de primeras letras arreglado al nuevo sistema de Lancaster llamado de la enseñanza mutua, sacado de las Memorias de la Real Sociedad Económica de la Habana No. 10. Puebla: Oficina del Oratorio de San Felipe Neri, 1819 (Biblioteca La Fragua, Puebla). 2. Manual de enseñanza mutua para las escuelas de primeras letras de los Estados de la República Mexicana. México: Compañía lancasteriana, 1824. (Biblioteca Eusebio Kino, México). 

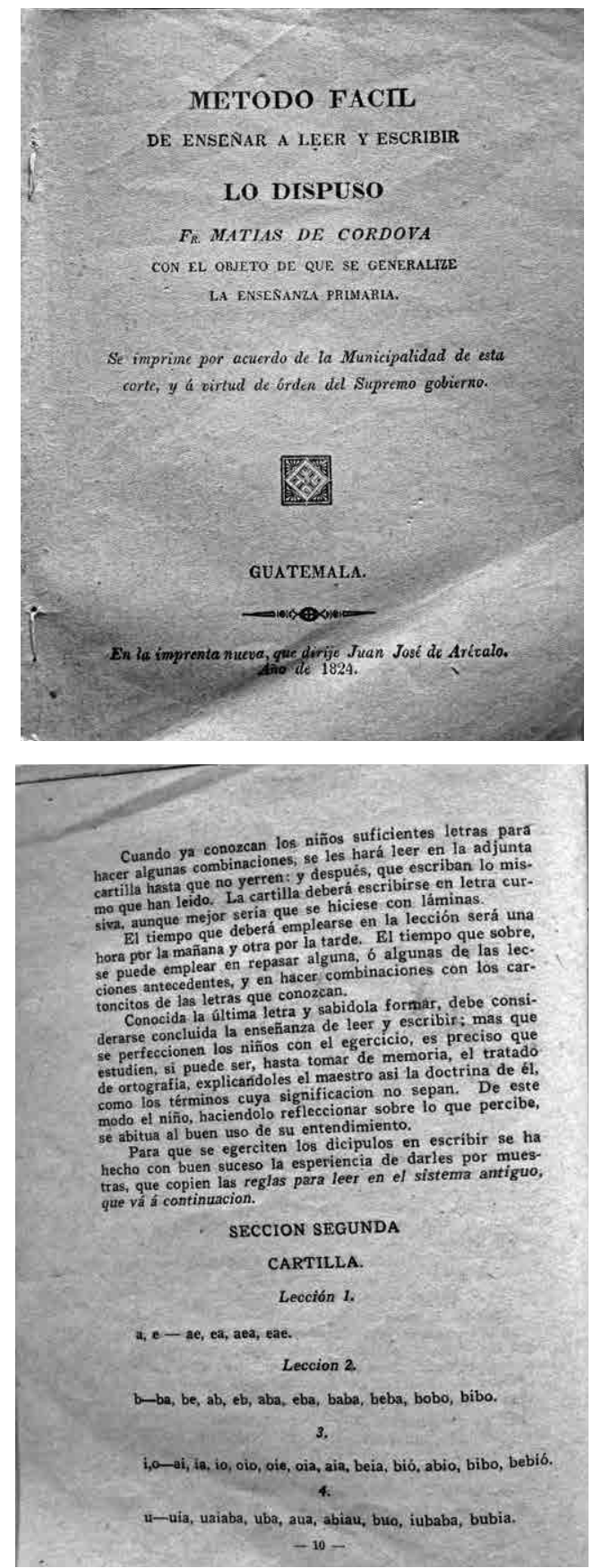

7. y 8. Matías de Córdova. Método fácil de enseñar a leer y escribir. Guatemala: La Imprenta Nueva, 1824. 


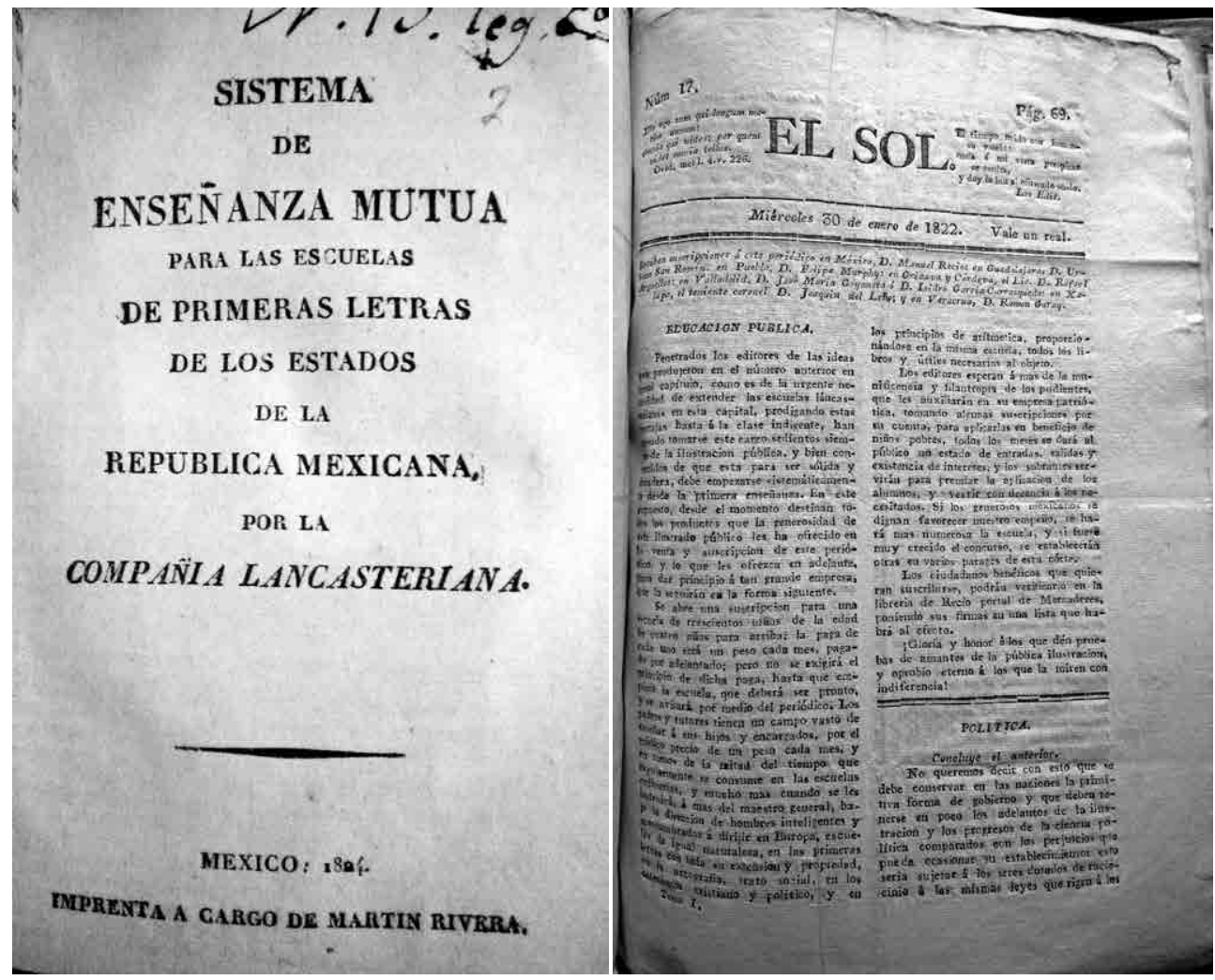

9. Manual de enseñanza mutua para las escuelas de primeras letras de los Estados de la República Mexicana. México: Compañía lancasteriana, 1824. (Biblioteca Eusebio Kino, México).

10. Periódico El Sol, No. 17 del 30 de enero de 1822, México: Archivo Histórico de la Ciudad de México.

Fotografías: Osvaldo Granda. 


\section{FUENTES}

Archivos, BibliotecAS y HeMERotecas.

Archivo del Ayuntamiento de México, AAM.

Archivo General de Indias en Sevilla, AGI.

Archivo Histórico Nacional, Madrid. AHN.

Archivo General de la Nación, Bogotá. AGN.

Hemeroteca Nacional de México, HNM.

Biblioteca "La Fragua”, Puebla.

Biblioteca Nacional de Colombia.

Gazeta de México. México: editada por Manuel Antonio Valdés y Murguía, tomo II, 1786-87 y tomo III, 1788.

Gaceta del Gobierno de México. México: Imp. Juan Bautista de Arizpe. Tomo X, 1819.

Noticioso General. México: Imprenta de Benavente, y otras. Julio a diciembre de 1815.

Noticioso General. México: Imprenta de Arizpe. Años 1818 y 1819.

Periódico de la Sociedad Económica de Guatemala: Guatemala, 1815-1816.

Estatutos de la Real Sociedad Económica de Amantes de la Patria de Guatemala. Guatemala: Ignacio Beteta, 1796.

Junta Pública de la Real Sociedad Económica de Amantes de la Patria de Guatemala. Guatemala: Alexo Bracamonte1796.

Segunda Junta Pública de la Real Sociedad Económica de Amantes de la Patria de Guatemala. Guatemala: Viuda de Sebastián de Arévalo, 1797.

Cuarta Junta Pública de la Real Sociedad Económica de Amantes de la Patria de Guatemala. Guatemala: Viuda de Sebastián de Arévalo, 1798.

Aviso al público. Guatemala: Real Sociedad Económica de Amantes de la Patria de Guatemala, 1796, [hoja suelta].

Memorias de la Sociedad Económica de Amantes de Guatemala. Guatemala: Imp. de la Unión, 1830.

Memorias de la Sociedad Económica de Amigos de Guatemala. Guatemala: Imp. de Luna, 1861 Memorias de la Real Sociedad Económica de La Habana, La Habana, Imp. del gobierno, 1817. Memorias de la Real Sociedad Económica de La Habana, La Habana, Imp. del gobierno, 1818. Memorias de la Sociedad Patriótica de La Habana. La Habana: Imp. del Gobierno, 1829.

\section{REFERENCIAS}

Amunátegui Solar, Domingo. El sistema de Lancáster en Chile y en otros países sudamericanos. Santiago: Imp. Cervantes, 1895.

Araújo, Orestes. Historia de la escuela uruguaya. Montevideo: Dirección General de Instrucción Primaria, 1911.

Barrios Pintos, Aníbal. Paysandú: historia general. Vol. II. Montevideo: Intendencia Municipal de Paysandú, 1989.

Blanco-Fombona. Cartas de Bolívar 1825, 1826, 1827. s.f. 
Bolívar, Simón. Proyecto de Constitución para la República de Bolivia y Discurso del Libertador. Bogotá: S. S. Fox, 1826.

Calderón España, Ma. Consolación y Ma. Isabel Corts Giner. Ofertas educativas de las Reales Sociedades Económicas de Amigos del País en Latinoamérica (Siglos XVIIIXIX). $\quad$ http://ddfv.ufv.es/bitstream/handle/10641/961/Ofertas\%20educativas. pdf?sequence=1, 2006.

Calvo, José María. Cartilla rústica para las escuelas del campo. La Habana: Severino Boloña, 1842.

Contreras García, Irma. Las etnias del Estado de Chiapas: castellanizacioń y bibliografías. México: UNAM, 2001.

De la Torre Villar, Ernesto. Lecturas Históricas Mexicanas. México: UNAM, 1998.

De la Torre, Ernesto. «Francisco Pérez Salazar.» Editado por http://www.historicas.unam. $\mathrm{mx} /$ publicaciones/publicadigital/libros/lecturas/T3/LHMT3_069.pdf. Lecturas históricas mexicanas (Instituto de Investigaciones Históricas), 1/12/16: 605-615.

Establecimiento de la junta de caridad y sociedad patriótica para la buena educación de la juventud en la ciudad y estado de la Puebla de Los Angeles. México: Impr. Nacional, 1825.

Gárate Ojanguren, Montserrat. La Real Sociedad Bascongada de Amigos del País y América. http://bascongada.eus/es/la-sociedad/historia/158-la-real-sociedad-bascongadade-amigos-del-pais-y-america, 2/6/2016.

García Dávalos, Luis Arturo. La Real Junta de Caridad y Sociedad Patriótica para la buena educación de la juventud de la ciudad de Puebla de los Ángeles en la América Septentrional y la introducción en Nueva España del método Lancasteriano. México: https://www.academia.edu/11585452/La_Real_Junta_de_Caridad_y_Sociedad_ Patri\%C3\%B3tica_para_la_buena_educaci\%C3\%B3n_de_la_Juventud_de_ la_ciudad_de_Puebla_de_los_\%C3\%81ngeles_en_la_Am\%C3\%A9rica_ Septentrional_y_la_introducci\%C3\%B3n_en_Nueva_Espa\%C3\%B1a_del_M, 8/9/2016.

García Dávalos, Luis Arturo. Teología sociedad y política en la transición al México independiente. El pensamiento de Pablo Vázquez (1768-1825). México: Tesis: Tesis doctoral en Historia, UNAM, 2015.

Gaudiano, Pedro. Artigas católico. Montevideo: Universidad Católica del Uruguay, 2002.

Giner, $\mathrm{M}^{\mathrm{a}}$ Consolación Calderón España y $\mathrm{M}^{\mathrm{a}}$ Isabel Corts. Ofertas educativas de las reales sociedades económicas de amigos del país en latinoamérica (siglos XVIII-XIX). http:// ddfv.ufv.es/bitstream/handle/10641/961/Ofertas\%20educativas.pdf?sequence=1, 2006. (15/1/2009).

Guía de forasteros de la isla de Cuba y calendario manual para el año de 1814. Habana: Oficina de Arazoza y Soler, 1814.

Guzmán Pérez, Moisés. «Impresores y editores de la independencia de México. 18081821.» Editado por Instituto de Investigaciones Dr. José Luis Mora. Secuencia. Revista de historia y ciencias sociales, No. 81 (2011): 187-193.

Huerta Martínez, Ángel . La enseñanza primaria en Cuba en el siglo XIX (1812-1868). Sevilla: Excma. Diputación Provincial de Sevilla, 1992.

Huerta Martínez, Ángel. La enseñanza primaria en Cuba en el siglo XIX (1812-1868). Sevilla: Excma. Diputación Provincial de Sevilla, 1992.

Luque Alcaide, Elisa. La educación en Nueva España en el siglo XVIII. Sevilla: EEHA, 1970. 
Manual práctico del método de mutua enseñanza para las escuelas de primeras letras. Cádiz, Imp. de Hércules: Sociedad Económica de Amigos del País de Cádiz, 1818.

Márquez Carrillo, Jesús. Escuela gratuita del seminario de Puebla y su importancia (17961823). México: www.comie.org.mx/congreso/memoriaelectronica/v09/.../at09/ PRE1178818925.pdf, 19/10/2015.

Márquez Carrillo, Jesús. La obscura llama. Élites letradas, política y educación en Puebla,1750-1850. Puebla: Ediciones de Educación y Cultura-Dirección de Fomento Editorial- Facultad de Filosofía y Letras-Benemérita Universidad Autónoma de Puebla, 2012.

Mendarte Rocandio, Félix. Arte para la primera enseñanza de niños y niñas por el sistema mutuo: Acompañado de 28 muestras y todas las teorías que necesita cada escuela... Veracruz Imprenta del autor: Imp. del autor, 1828.

Mendarte Rocandio, Félix. Prospecto (de la Obra Que Anuncio Titulada "Arte para la Primera Enseñanza de Niños y Niñas por el Sistema Mutuo, Acompañado de las Muestras de Escribir"). 1827.

Origen y progresos del nuevo sistema de enseñanza mutua del señor Lancaster, traducido del inglés. Buenos Aires: Imp. de los Expósitos, 1820.

Paz, José Ignacio. Al exmo. Señor don Juan Ruiz de Apodaca Conde del venadito. En obsequio de la pública educación primaria, dedica este defectuoso prospecto su humilde autor. México: Jaun Bautista de Arizpe, 1819.

Paz, Jose Ignacio. En obsequio de la pública educación primaria, dedica este defectuoso Prospecto su humilde autor. México: Juan Bautista de Arizpe, 1819.

Pérez de los Reyes, Marco A. «Fray Matías de Córdova. Su vida y su obra» En Memoria del IV Congreso de Historia del Derecho, de Beatriz (Coord.) Bernal, 857-870. México: UNAM-Instituto de Investigaciones Jurídicas, 1988.

Pineda, Lubia Esperanza. La Educación en Guatemala durante el régimen de Mariano Gálvez. Guatemala: Tesis de Licenciatura USAC, 1991.

Real Sociedad Bascongada de los Amigos del País. Extractos de las juntas celebradas por la Real Sociedad Bascongada de los Amigos del País. Vitoria: Tomás de Robles, 1772.

Real Sociedad Económica de Amantes de la Patria de Guatemala. Estatutos de la Real Sociedad Económica de Amantes de la Patria de Guatemala. Guatemala: Ignacio Beteta, 1796.

Real Sociedad Económica de La Habana. «Memorias de la Real Sociedad Económica de La Habana» Colección primera que comprende doce números correspondientes a los doce meses del año de 1817, febrero de 1817.: 331-380.

Real Sociedad Económica de La Habana. Memorias de la Real Sociedad Económica de La Habana, 1818.

Real Sociedad Económica de La Habana. Memorias de la Real Sociedad Económica de La Habana. Habana: Imp. del Gobierno, 1817.

Rivera, Manuel. Historia antigua y moderna de Jalapa y de las revoluciones del Estado de Veracruz. México: Cumplido, 1869.

Roldán Vera, Eugenia. «El sistema de enseñanza mutua y la cultura cívica durante los primeros años de la república independiente de México» Historia Caribe (U. del Atlántico) II, no 7 (2002): 113-136.

Shafer, Robert Jones. The Economic Societies in the Spanish World (1763-1821). Syracuse University, 1958. 
Solari, Manuel Horacio. Historia de la educación argentina. Buenos Aires: Paidós, 1991.

Sucre, Antonio José. De mi propia mano. Editado por J. L. Salcedo Bastardo / Tomás Straka. Caracas: Fund. Biblioteca Ayacucho, 1981.

Tanck de Estrada, Dorothy. «Innovaciones en la enseñanza de la lectura en el México independiente, 1821-1840.» Nueva Revista de Filología Hispánica 38, noำ (1990): 141162.

Tanck de Estrada, Dorothy. «Las escuelas lancasterianas en la ciudad de México, 18221842» Historia Mexicana 22, n. 4 (1973): 494-513.

Tanck Estrada, Dorothy. La educación ilustrada 1786-1836. México: El Colegio de México, 2005.

Thomson. Letters on the moral and religious state of South America, written during a residence of nearly seven years in Buenos Aires, Chile, Perú and Colombia. London, 1827.

Thomson, James D. «A la comisión de la Sociedad de Escuelas Británicas i Estranjeras.» Repertorio americano 2 (1827): 61-75.

Torales Pacheco, María Cristina. Ilustrados en la Nueva España: los socios de la Real Sociedad Bascongada de Amigos del País. México: Universidad Iberoamericana, 2001.

Vaughan, E. Lancaster en Caracas (1824-1827). Caracas: Ministerio de Educación, 1987.

Yépez Castillo, Áureo. La educación primaria en Caracas en la época de Bolívar. Caracas: ANH, 1985.

Granda Paz, Osvaldo. "Introducción de la enseñanza mutua en las escuelas de Cuba, Guatemala y México". Revista Historia de la Educación Latinoamericana. Vol. 19 No. 29 (2017): 219-244. 